\title{
Involvement of microRNAs in epigallocatechin gallate-mediated UVB protection in human dermal fibroblasts
}

\author{
IN-SOOK AN ${ }^{1 *}$, SUNGKWAN AN $^{2 *}$, SEYEON PARK $^{3}$, SUNG NAE LEE $^{4}$ and SEUNGHEE BAE ${ }^{2}$ \\ ${ }^{1}$ Korea Institute for Skin and Clinical Sciences; ${ }^{2}$ Molecular-Targeted Drug Research Center, Konkuk University, \\ Seoul 143-701; ${ }^{3}$ Department of Applied Chemistry, Dongduk Women's University, Seoul 136-714; \\ ${ }^{4}$ Department of Cosmetology, Kyung-In Women's College, Incheon 407-740, Republic of Korea
}

Received June 26, 2012; Accepted September 21, 2012

DOI: $10.3892 / o r .2012 .2083$

\begin{abstract}
The green tea polyphenol epigallocatechin3-gallate (EGCG) is a potent anti-oxidant and anticancer compound. Recently, EGCG-mediated UVB photoprotection was reported in normal human dermal fibroblasts (NHDFs); however, the molecular mechanism underlying this process remains unknown. Thus, we investigated the EGCG-specific microRNAs (miRNAs) involved in the UVB protective response in NHDFs. WST-1 assays confirmed that low doses $(<50 \mu \mathrm{M})$ of EGCG were non-cytotoxic and capable of recovering NHDF cell viability following UVB irradiation up to $83.7 \%$ compared to the control cells. Microarray analysis identified several miRNAs that were upregulated and downregulated significantly in this UVB protective response, with downregulated miRNAs outnumbering the upregulated ones. Bioinformatic studies, including miRNA target gene prediction and gene ontology analysis, revealed that the EGCG-specific miRNAs may control genes involved in transcription regulation and inhibition of apoptosis, but not MAPK activation, in NHDFs. Therefore, these results suggest that EGCG may serve as a potential natural photoprotective agent against UVB-mediated damage in NHDFs by altering specific miRNA expression.
\end{abstract}

\section{Introduction}

Epigallocatechin-3-gallate (EGCG), which is also known as catechin, is the most abundant polyphenolic compound extracted from green tea (1). Numerous reports have demonstrated the beneficial health effects of EGCG in cancer, anti-oxidation, inflammation and hypertension (2-6). Moreover, EGCG exhibits an anti-photoaging effect in skin cells. Ultraviolet (UV) radia-

Correspondence to: Dr Seunghee Bae, Molecular-Targeted Drug Research Center, Konkuk University, 1 Hwayang-dong, Gwangjin-gu, Seoul 143-701, Republic of Korea

E-mail:sbae@konkuk.ac.kr

${ }^{*}$ Contributed equally

Key words: epigallocatechin gallate, dermal fibroblast, UVB irradiation, miRNA expression, cell viability tion is the main inducer of photoaging, which is characterized by collagen loss, reactive oxygen species (ROS) generation, cell senescence and apoptosis. In vitro studies have demonstrated that EGCG protects against oxidative cellular damage in skin cells caused by UV radiation (7). Studies in mice demonstrated that EGCG prevents photocarcinogenesis through DNA repair (8). Furthermore, EGCG pretreatment inhibited UVB-mediated thinning of the epidermis, thereby restoring epidermal thickness and rendering the basal layer more compact in living skin equivalents (9). Together, these results suggest that EGCG is a potential agent for preventing photoaging in skin.

Although the anti-photoaging effect of EGCG on skin cells has been broadly researched, molecular studies investigating the EGCG-mediated UVB protective effect have been limited. In keratinocytes, EGCG inhibited UVB-induced activation of activator protein-1 (AP-1) and p38 mitogen-activated protein kinase (MAPK) (10). In addition, UVB-induced NF- $\kappa$ B activation and IL-6 expression were attenuated by EGCG treatment (11). One molecular study investigating dermal fibroblasts reported that EGCG may prevent UVB-induced collagenolytic MMP production by interfering with the MAPK pathways (12). Despite this knowledge, the molecular mechanisms underlying the anti-photoaging effect of EGCG remain largely unknown.

microRNAs (miRNAs) are small ( 19 nt), non-coding RNA molecules expressed in eukaryotes that regulate gene expression by inhibiting the translation of their target mRNA (13). These small RNA molecules play central roles in several biological and disease processes, including cell survival, apoptosis, metabolism, cancer and diabetes (14). miRNAs have also been associated with several important functions in skin cells. For example, miR-203 is expressed only in terminally differentiated cells and downregulates p63, an essential regulator of stem-cell maintenance, to enable pluripotent cells to differentiate into the stratified layers that compose the skin (15). Moreover, DGCR8mediated miRNA biogenesis is essential for skin development, indicating that miRNAs are an important regulator of mammalian skin development (16). Recent miRNA expression profiling analyses of UVB-irradiated normal human keratinocytes have revealed several specific miRNA expression patterns (17). However, characterization of miRNA expression associated with the UVB-protective ability in human dermal fibroblasts has yet to be performed. In this current study, we conducted miRNA expression profiling of EGCG-treated normal human 

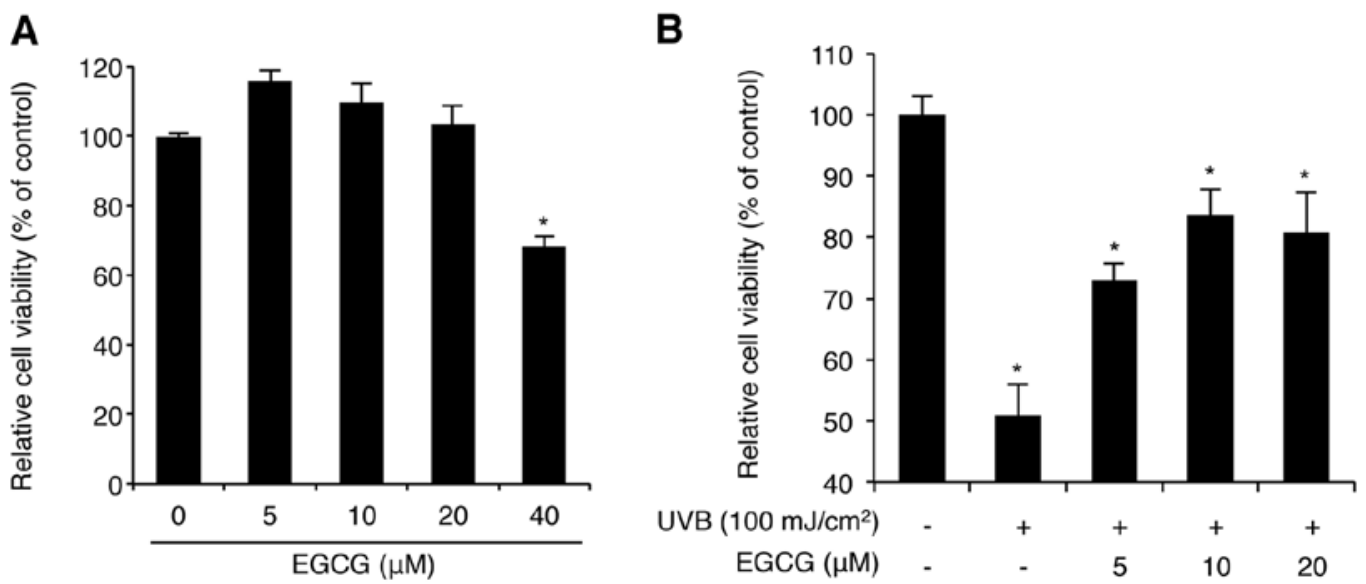

Figure 1. EGCG has low cytotoxicity and exhibits a UVB protective effect on NHDFs. (A) The effect of EGCG treatment on NHDF cell viability. NHDFs were treated with various concentrations of EGCG for $24 \mathrm{~h}$, and then WST-1 assays were performed to determine EGCG cytotoxicity. Data were obtained from triplicate experiments and are represented as the means \pm SD. (B) The protective effect of EGCG against UVB irradiation. NHDFs were pre-treated with EGCG prior to UVB irradiation, incubated again with the same dose of EGCG for $24 \mathrm{~h}$, and then subjected to the WST-1 assay. Data were obtained from triplicate experiments and are represented as the means $\pm \mathrm{SD}$. ${ }^{*} \mathrm{p}<0.05$ compared to the negative control.

dermal fibroblasts (NHDFs). Our data demonstrate that the antiphotoaging effect of EGCG induced several specific miRNA expression patterns involved in cell proliferation.

\section{Materials and methods}

Cell culture. NHDFs were purchased from Lonza (Basel, Switzerland) and cultured in Dulbecco's modified Eagle's medium (DMEM, Gibco, Invitrogen, Carlsbad, CA, USA) supplemented with $10 \%$ fetal bovine serum (FBS; SigmaAldrich, St. Louis, MO, USA), penicillin (100 U/ml) and streptomycin $(100 \mu \mathrm{g} / \mathrm{ml})$. The cells were incubated at $37^{\circ} \mathrm{C}$ in a humidified atmosphere containing $5 \% \mathrm{CO}_{2}$.

Cytotoxicity and UVB protection assay. NHDFs $\left(3 \times 10^{3}\right)$ were seeded into 96-well plates and incubated overnight before treatment with several concentrations of EGCG for $24 \mathrm{~h}$. The cytotoxicity of EGCG was measured by the WST-1 assay (EZ-CytoX Enhanced cell viability assay kit; Daeil Lab Service, Seoul, Korea) according to the manufacturer's instructions.

To assess UVB protection, NHDFs were first pre-treated with DMSO (Sigma-Aldrich) or EGCG (Sigma-Aldrich) for $3 \mathrm{~h}$. Then the cells were washed and exposed to $100 \mathrm{~mJ} / \mathrm{cm}^{2}$ UVB without protective filters. After irradiation, the cells were cultured in tissue culture media with DMSO or EGCG for an additional $24 \mathrm{~h}$ before cell viability was measured using the WST-1 assay.

RNA purification. Total RNA was extracted using TRIzol reagent (Invitrogen) according to the manufacturer's instructions. The integrity of each RNA sample was verified with an Agilent 2100 Bioanalyzer ${ }^{\circledR}$ (Agilent Technologies, Santa Clara, CA, USA). A260/A230 and A260/A280 ratios between 1.8 and 2.1 were confirmed in all RNA samples using the MaestroNano ${ }^{\circledR}$ spectrophotometer (Maestrogen, Las Vegas, NV, USA).

Microarray analysis of miRNA profiles. miRNA profiling analysis was performed using SurePrint G3 Human V16
miRNA 8x60K microarrays (Agilent Technologies) containing probes for 1205 human and 144 viral miRNAs. Each RNA sample was dephosphorylated, labeled with Cyanine 3-pCp using T4 RNA ligase, dried completely and then treated with GE blocking agent (Agilent Technologies). The RNA was applied to the microarrays and then placed in the Agilent microarray hybridization chamber (Agilent Technologies) for $20 \mathrm{~h}$. The microarrays were imaged using an Agilent scanner, and quantitative data for the miRNA profiles were extracted from the images using the Feature Extraction program (Agilent Technologies). These data were analyzed with GeneSpring GX software version 7.3 (Agilent Technologies). miRNAs with flags present in at least one sample were filtered and subjected to fold-change analysis. The fold-change analysis was conducted by a factor of 1.5 -fold between the samples.

Computational analysis of miRNA expression. miRNAs that exhibited significant differential expression were selected, and their putative cellular target genes were determined using microCosm Target version 5 (www.ebi.ac.uk/enright-srv/ microcosm/htdocs/targets/v5/). Target genes were categorized into four groups, namely aging, apoptosis, cell proliferation, and skin development, using the Gene Ontology analysis tool AmiGO (amigo.geneontology.org/cgi-bin/amigo/browse.cgi). The genes were then further categorized into groups such as anti-apoptosis, activation of MAPKK activity, Ras protein signal transduction, small GTPase-mediated signal transduction, positive or negative regulation of cell growth, cell proliferation, cell cycle and regulation of transcription.

\section{Results and Discussion}

Before assessing the protective activity of EGCG against UVB radiation, we investigated the cytotoxicity of this compound on NHDFs at various doses. WST-1-based cell proliferation analysis demonstrated that 5-20 $\mu \mathrm{M}$ of EGCG for $24 \mathrm{~h}$ did not affect cell viability, whereas a $40 \mu \mathrm{M}$ dose decreased cell viability to below $65 \%$ (Fig. 1A). In fact, a previous 
A

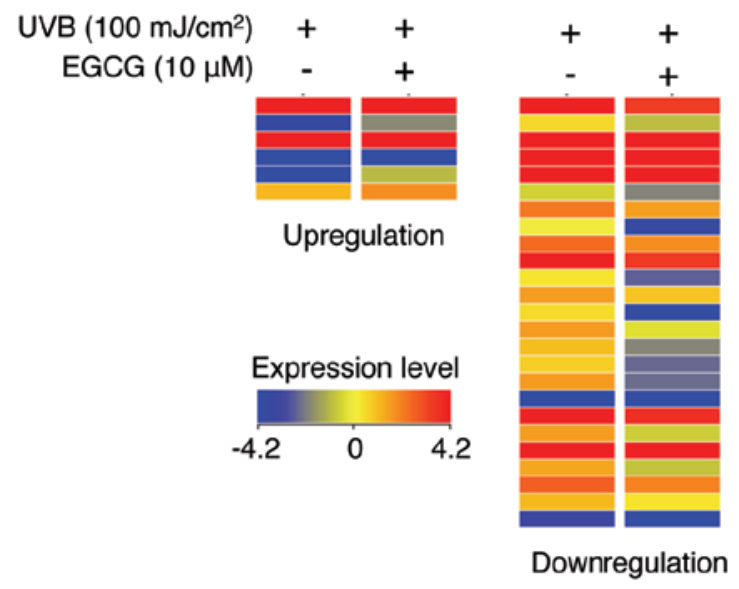

B

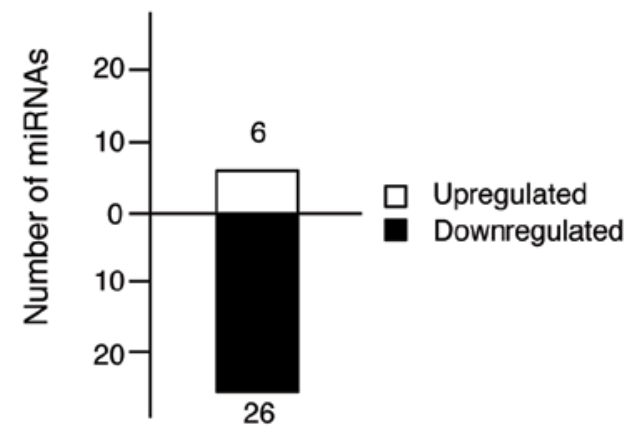

Figure 2. Changes in miRNA expression are associated with EGCG-mediated UVB protective mechanisms in NHDFs. (A) The UVB-protective action in EGCG treatment of NHDFs involves upregulation and downregulation of miRNA expression. The heat map generated from our miRNA microarray analysis depicts miRNAs that were altered by at least $>1.2$-fold. (B) The total number of miRNAs upregulated and downregulated by EGCG in response to UVB radiation in NHDFs.

Table I. miRNAs exhibiting a greater than 1.2-fold change in expression upon EGCG treatment in UVB-exposed NHDFs.

\begin{tabular}{llllr}
\hline miR name & FC & Chr & \multicolumn{1}{c}{ miR name } & FC \\
\hline hsa-miR-1246 & 1.23 & - & hsa-miR-212 & Chr17 \\
hsa-miR-145* & 1.32 & Chr22 & hsa-miR-3141 & Chr1 \\
hsa-miR-4299 & 1.29 & Chr9 & hsa-miR-3610 & -1.23 \\
hsa-miR-548c-3p & 1.36 & Chr16 & hsa-miR-362-3p & -2.17 \\
hsa-miR-636 & 2.70 & Chr19 & hsa-miR-3667-5p & -1.70 \\
hsa-miR-933 & 1.25 & Chr12 & hsa-miR-3679-3p & -1.81 \\
ebv-miR-BART12 & -1.45 & Chr8 & hsa-miR-3907 & -1.77 \\
ebv-miR-BART1-1 & -1.36 & Chr11 & hsa-miR-423-3p & -2.30 \\
hsa-miR-1202 & -1.22 & Chr19 & hsa-miR-4270 & -2.09 \\
hsa-miR-1207-5p & -1.22 & Chr7 & hsa-miR-455-5p & -1.21 \\
hsa-miR-1225-5p & -1.23 & Chr8 & hsa-miR-494 & -1.77 \\
hsa-miR-1227 & -1.24 & Chr18 & hsa-miR-513a-5p & -1.29 \\
hsa-miR-1271 & -1.23 & Chr20 & hsa-miR-660 & -1.74 \\
hsa-miR-133a & -1.80 & ChrX & hsa-miR-718 & - \\
hsa-miR-134 & -1.21 & Chr3 & kshv-miR-K12-10b & Chr11 \\
hsa-miR-181d & -1.32 & Chr15 & & Chr7 \\
\hline
\end{tabular}

*Represents the passenger strand from the miRNA duplex. FC, fold change; Chr, chromosome.

report showed that treatment of NHDFs with $>50 \mu \mathrm{M}$ EGCG reduced cell viability by $50 \%$ as determined by the MTT assay (18). Thus, high doses $(>40 \mu \mathrm{M})$ of EGCG decrease cell viability, while low doses $(<40 \mu \mathrm{M})$ have no cytotoxic effects on NHDFs. Therefore, our analysis of EGCG-mediated UVB protection was performed using 5,10 , and $20 \mu \mathrm{M}$ of EGCG. We confirmed that treatment with $10 \mu \mathrm{M}$ of EGCG rescued NHDFs from UVB radiation $\left(100 \mathrm{~mJ} / \mathrm{cm}^{2}\right)$-mediated cell death up to $83.7 \%$ compared with the control NHDFs (Fig. 1B). These results are consistent with previous studies (12), indicating that EGCG has a strong photo-protective effect against UVB radiation on NHDFs.
Studies of the molecular details underlying this photoprotective effect have been focused on changes in MAPK activation, including JNK, p38 MAPK and ERK1/2 phosphorylation. However, these changes are not specific to EGCG-treated NHDFs. UVB radiation induces MAPK phosphorylation in a variety of cell types, including NHDFs, keratinocytes, melanocytes and cancer cells (19). Moreover, UVB radiation does not increase MAPK protein synthesis in cells, but rather the level of MAPK activity (19). Notably, several natural and chemical agents reported to exhibit a UVB photo-protective effect share similar mechanisms, including MAPK phosphorylation (20-23). These data indicate that, 
Table II. Predicted target genes of miRNAs upregulated in response to EGCG in UVB-exposed NHDFs.

\begin{tabular}{|c|c|c|c|c|}
\hline \multirow[b]{2}{*}{ miRNA } & \multicolumn{4}{|c|}{ Functions of target genes } \\
\hline & Aging & Apoptosis & Cell proliferation & Skin development \\
\hline hsa-miR-1246 & & AQP1 & $\begin{array}{l}\text { AQP1, AXIN2, GNRHR, } \\
\text { PTCH1 }\end{array}$ & - \\
\hline hsa-miR-548c-3p & $\begin{array}{l}\text { MME, SMC5, } \\
\text { MNT, SMC6, } \\
\text { BBC3, ID2, } \\
\text { NUAK1, } \\
\text { NR3C1 }\end{array}$ & $\begin{array}{l}\text { MNT, NR3C1, BBC3, CDKN1B, } \\
\text { BCL2L11, DLX1, FOXQ1, OGT, } \\
\text { UBE2B, WNK3, TCFL2, BDNF, } \\
\text { RFFL, RPS6KA1, SNCA, TIA1, } \\
\text { AKAP13, PPARGC1A, PREX1, } \\
\text { CITED2, DLC1, ERBB4, FLT3, } \\
\text { FOXO1, HIPK2, LRP6, ATG5, } \\
\text { NFKBIA, SMAD3, TNFSF12, } \\
\text { TRIM24, PAK2, PKP1, CBL, } \\
\text { RPS6KA2, TGFBR2, PXN2, } \\
\text { PRKAA1, PSMD3, TRAF4 }\end{array}$ & $\begin{array}{l}\text { TNFSF12, TRIM24, DDR1, } \\
\text { PGR, UBR5, ODC1, TOB2, } \\
\text { ID4, LRP6, HSF1, FOXO1, } \\
\text { HIPK2, NFKBIA, SMAD3, } \\
\text { NUAK1, CITED2, ERBB4, } \\
\text { MMP12, MMP14, PBRM1, } \\
\text { MNT, NR3C1, ID2, DLC1, } \\
\text { STAT3, VASH2, TCF7L2, } \\
\text { ODZ1, TOB1, RPS6KA2, } \\
\text { FLT3, CDKN1B, HMX2, } \\
\text { IRF6, TGFBR2, BDNF }\end{array}$ & $\begin{array}{l}\text { DDR1, IRF6, } \\
\text { TCF7L1, TCF7L2, } \\
\text { FRAS1 }\end{array}$ \\
\hline hsa-miR-636 & SOCS3 & $\begin{array}{l}\text { RPS6KA3, SENP1, CBL, PKN2, } \\
\text { SOCS3, MITF, SFRP2, TRAF5, } \\
\text { PCGF2, PRKCE, PROC, RTN3, } \\
\text { ACTN1, ARF6, GRIK2, ITSN1, } \\
\text { YWHAZ, TCF7L2, RPS6KA2, } \\
\text { TGFBR2 }\end{array}$ & $\begin{array}{l}\text { TRAF5, BCAT1, FBXW7, } \\
\text { MITF, SFRP2, RPS6KA2, } \\
\text { TCF7L2, RNF139, TOB1, } \\
\text { EMX2, LIFR, SSR1, } \\
\text { TGFBR2 }\end{array}$ & TCF7L2 \\
\hline hsa-miR-933 & - & BDNF & BDNF & - \\
\hline
\end{tabular}

although the MAPK pathways are important regulators in photo-protective mechanisms, their activity is not specific to the protection against UVB radiation. Besides these signaling pathways, EGCG-mediated anticancer properties have been associated with changes in the expression of specific miRNAs, namely miR-16 and miR-210, indicating that EGCG may function by regulating miRNA expression $(24,25)$. Therefore, we proceeded to identify the specific regulators of the EGCGmediated photo-protective effect on NHDFs using miRNA expression profiling analysis that also demonstrated tissueand process-specific expression of miRNAs in various reports $(26,27)$.

The Agilent SurePrint G3 Human v16 miRNA microarray, which contains probes representing 1205 human and 144 viral miRNAs, was used to investigate changes in miRNA expression induced by EGCG treatment of UVB-irradiated NHDFs. Our study revealed that 6 and 26 miRNAs were upregulated and downregulated greater than 1.2-fold, respectively (Fig. 2). These miRNAs are listed in Table I. With a 2.7-fold increase, miR-636 exhibited an increased upregulation. miR-3907, which displayed a 2.30-fold decrease, was downregulated to the greatest extent in this experiment. These data suggest that these miRNAs may be novel targets of EGCG. Of note, the microarray results showed that the number of downregulated miRNAs was higher than the number of upregulated miRNAs, indicating that the EGCG-mediated photo-protective effect is associated more with miRNA downregulation. miR-133a and miR-212, which were downregulated 1.8- and 1.61-fold, respectively, have been reported to induce apoptosis in bladder cancer and non-small cell lung cancer cells $(28,29)$. In addition, miR-513a-5p, which was downregulated 1.74-fold in our study, reportedly mediates TNF- $\alpha$ - and LPS-induced apoptosis in human umbilical vein endothelial cells (30). Although such miRNAs have not been associated with UVB-mediated apoptosis, these results suggest that EGCG inhibits UVB-mediated NHDF cell death by downregulating apoptosis-related miRNAs. Overall, these results indicate that EGCG may regulate specific miRNA expression levels to mediate UVB photoprotection.

miRNAs function by engaging with their target mRNA and inhibiting its translation (13). We used the MicroCosm Target tool to identify putative miRNA target genes, analyze their gene ontology, and categorize them into cellular processes including aging, apoptosis, cell proliferation, and skin development (Tables II and III). Furthermore, target genes were re-analyzed and categorized according to the cellular mechanisms to which they are related, as represented in Table IV. Of note, the genes targeted by the downregulated miRNAs are mainly involved in regulating transcription, anti-apoptosis, cell division, cell cycle and small GTPase-mediated signal transduction. However, these target genes are not involved in MAPK-related mechanisms, indicating that the miRNA-based EGCG-mediated photo-protective response is controlled by specific miRNAs and target genes associated with transcription and cell survival, but not MAPK activation, in NHDFs.

In summary, to the best of our knowledge, we demonstrated for the first time that EGCG protects against UVB radiation by regulating specific miRNAs that putatively target 
Table III. Predicted target genes of miRNAs downregulated in response to EGCG in UVB-exposed NHDFs.

\begin{tabular}{|c|c|c|c|c|}
\hline \multirow[b]{2}{*}{ miRNA } & \multicolumn{4}{|c|}{ Functions of the target genes } \\
\hline & Aging & Apoptosis & Cell proliferation & Skin development \\
\hline hsa-miR-1202 & SLC1A2 & $\begin{array}{l}\text { DSP, NAIF1, ETS1, SOS1, UBD, } \\
\text { RALB }\end{array}$ & $\begin{array}{l}\text { ARNT, GABBR1, BCAT1, } \\
\text { HOOK3, ETS1 }\end{array}$ & DSP \\
\hline hsa-miR-1207-5p & LRP1 & $\begin{array}{l}\text { IGF1, MKL1, FGFR1, UBE2Z, } \\
\text { CBL, NOL3, TNS4, EGLN2 }\end{array}$ & $\begin{array}{l}\text { LRP1, FGFR1, ACVRL1, } \\
\text { IGF1, CYP27B1 }\end{array}$ & - \\
\hline hsa-miR-1225-5p & - & KIAA1324, PEG10 & ELN, TAL1 & - \\
\hline hsa-miR-1227 & $\begin{array}{l}\text { TGFBR1, } \\
\text { SOCS3 }\end{array}$ & RTNFAIP8, TGFBR1, SOCS3 & TGFBR1, IRF2 & - \\
\hline hsa-miR-1271 & $\begin{array}{l}\text { MAP2K1, } \\
\text { EDNRA, } \\
\text { CASP2, } \\
\text { DDIT3, } \\
\text { PTEN }\end{array}$ & $\begin{array}{l}\text { TGFBR1, CASP2, ALK, DDIT3, } \\
\text { MED1, PROK2, DOCK1, OGT, } \\
\text { KPNB1, MBD4, SORT1, TRIB, } \\
\text { EDNRA, FOXO1, TNFSF13B, } \\
\text { ECE1, PRKCE, PTEN }\end{array}$ & $\begin{array}{l}\text { PROK2, LAMC1, RNF139, } \\
\text { TNFSF13B, CD164, ALK, } \\
\text { EDNRA, MED1, MYO16, } \\
\text { FOXO1, LIPG, MAP2K1, } \\
\text { TNS3, NEUROD4, IRS1, } \\
\text { KRAS, PTEN }\end{array}$ & - \\
\hline hsa-miR-133a & $\begin{array}{l}\text { ZNF354A, } \\
\text { PML }\end{array}$ & $\begin{array}{l}\text { RB1CC1, FOXC1, FOXL2, PML, } \\
\text { MCL1, SGK1, CYLD, EPHA7, } \\
\text { SOX4, RFFL, SGPP1, FOXQ1 }\end{array}$ & $\begin{array}{l}\text { PML, SGK1, SOX4, FGF1, } \\
\text { APPL2, BRD4, TXLNA, } \\
\text { CNN2, FOXC1, ENPEP, } \\
\text { LHX5, NPPC }\end{array}$ & - \\
\hline hsa-miR-134 & SEPRINE1 & $\begin{array}{l}\text { BDNF, STAT5B, ANGPTL4, } \\
\text { PDCD7, WWOX, SERPINE1 }\end{array}$ & $\begin{array}{l}\text { BDNF, STAT5B, FOXP2, } \\
\text { SERPINE1 }\end{array}$ & - \\
\hline hsa-miR-181d & $\begin{array}{l}\text { ATM, TIMP3, } \\
\text { ADRBK1, } \\
\text { PRKCD, } \\
\text { SIRT1 }\end{array}$ & $\begin{array}{l}\text { IL1A, GATA6, CBX4, HSP90B1, } \\
\text { ITSN1, RAD21, RNF34, UBE2B, } \\
\text { TNF, PRKCD, BAG4, BCL2L11, } \\
\text { CARD11, USP47, ATM, DDIT4, } \\
\text { BIRC6, INSL3, IRS2, NOTCH2, } \\
\text { PDCD6IP, UNC5A, TRIM2, } \\
\text { SIRT1 }\end{array}$ & $\begin{array}{l}\text { S1PR1, KRAS, SIRT1, LIF, } \\
\text { PRKCD, BIRC6, CARD11, } \\
\text { ATM, IL1A, INSL3, IRS2, } \\
\text { PROX1, RBBP7, GATA6, } \\
\text { NOTCH2, CDON, ING5, } \\
\text { PLAU, PDAP1, PRDM4, } \\
\text { LRRC32, TNF, MCC, CBLB }\end{array}$ & - \\
\hline hsa-miR-212 & CTGF & $\begin{array}{l}\text { CTGF, EP300, FOXA1, MAPK3, } \\
\text { FOXO3, ISL1, SGK3, MAPT, } \\
\text { RB1, RASA1 }\end{array}$ & $\begin{array}{l}\text { CTGF, FOXO3, ISL1, RB1, } \\
\text { SGK3, EGR1, SPRY1, } \\
\text { ZEB2, SOX11 }\end{array}$ & - \\
\hline hsa-miR-362-3p & GRB2 & $\begin{array}{l}\text { CUL2, KRIT1, BCLAF1, GRIK2, } \\
\text { BLCAP, PTPRJ, PRUNE2, SHB, } \\
\text { PRKCA }\end{array}$ & $\begin{array}{l}\text { BMPR2, CSF1R, PTPRJ, } \\
\text { CDK2, TXLNA, VSX2, } \\
\text { GPC3, OSM, PRKCA }\end{array}$ & - \\
\hline hsa-miR-455-5p & LRP2, SOCS3 & $\begin{array}{l}\text { FZD5, SOCS3, TJP1, ETS1, GPI, } \\
\text { KPNA1, KDR }\end{array}$ & $\begin{array}{l}\text { LRP2, FZD5, KDR, ETS1 } \\
\text { PDGFRA, IRF2, SOX11 }\end{array}$ & - \\
\hline hsa-miR-494 & $\begin{array}{l}\text { BBC3, CNR1, } \\
\text { SLC1A2, PTEN, } \\
\text { SIRT1 }\end{array}$ & $\begin{array}{l}\text { BBC3, CNR1, ROCK1, KPNA1, } \\
\text { CUL3, FGFR2, IGF1R, GULP1, } \\
\text { MTDH, UACA, PTEN, SIRT1, } \\
\text { INHBB }\end{array}$ & $\begin{array}{l}\text { PHOX2B, FGFR2, IGF1R, } \\
\text { CUL3, IL12B, ARHGAP5, } \\
\text { EVI5, GPNMB, PBRM1, } \\
\text { RAP1B, PTEN, TACC1, } \\
\text { NFIB, PITX, SIRT1 }\end{array}$ & - \\
\hline hsa-miR-513a-5p & $\begin{array}{l}\text { HMGCR, } \\
\text { CHEK2, SERP1, } \\
\text { CDK6, GRB2 }\end{array}$ & $\begin{array}{l}\text { RAG1, UNC5D, ZNF346, EYA1, } \\
\text { TRIM2, USP47, XIAP, MAPK7, } \\
\text { CHEK2, NOD2 }\end{array}$ & $\begin{array}{l}\text { MAGI2, PDS5B, SMAD2, } \\
\text { TBX19, KRAS, CBLB, } \\
\text { CDK6, EYA1, NOD2, } \\
\text { XIAP, ATF3, DDX11, } \\
\text { S1PR1, LIFR, VSX2 }\end{array}$ & - \\
\hline hsa-miR-660 & - & TFAP2B, CDH13, HIPK1 & $\begin{array}{l}\text { TFAP2B, CDH13, HIPK1, } \\
\text { NAP1L1, LIFR }\end{array}$ & TFAP2B \\
\hline
\end{tabular}


Table IV. Gene ontology analysis of the putative miRNA target genes.

Target genes of the upregulated miRNAs

Gene ontology

$\%$ of total ${ }^{\mathrm{a}}$

Negative regulation of transcription

20.0

Positive regulation of transcription

Nerve growth factor receptor signaling pathway

Cell cycle

19.1

Blood coagulation

20.0

Neural tube closure

5.2

Target genes of the downregulated miRNAs

Gene ontology

$\%$ of total

Chromatic modification

9.0

Positive regulation of transcription

14.2

Negative regulation of transcription

9.5

Cell division

10.4

Anti-apoptosis

6.8

Gene expression

11.2

Response to DNA damage stimulus

4.4

Cell cycle

10.6

Small GTPase-mediated signal transduction

8.4

Ras protein signal transduction

3.3

Activation of pro-apoptotic gene products

2.2

Positive regulation of osteoblast differentiation

2.2

Androgen receptor signaling pathway

2.5

Regulation of sequence-specific DNA

binding transcription factor activity

BMP signaling pathway

${ }^{a}$ Values were calculated by dividing the number of genes in each category by the total number of genes.

transcription- and cell survival-related genes in NHDFs. Although additional studies must be performed to verify the predicted miRNA target genes identified in this study, our results suggest that characterization of EGCG-specific miRNA changes may provide a useful approach to understanding cellular responses to EGCG in UVB-induced NHDF damage.

\section{Acknowledgements}

This work was supported by the Ministry of Education, Science and Technology (grant 20110028646 to S. An) of the Republic of Korea.

\section{References}

1. McKay DL and Blumberg JB: The role of tea in human health: an update. J Am Coll Nutr 21: 1-13, 2002.
2. Bettuzzi S, Brausi M, Rizzi F, Castagnetti G, Peracchia G and Corti A: Chemoprevention of human prostate cancer by oral administration of green tea catechins in volunteers with highgrade prostate intraepithelial neoplasia: a preliminary report from a one-year proof-of-principle study. Cancer Res 66: 1234-1240, 2006.

3. Yang CS, Lambert JD, Hou Z, Ju J, Lu G and Hao X: Molecular targets for the cancer preventive activity of tea polyphenols. Mol Carcinog 45: 431-435, 2006.

4. Stuart EC, Scandlyn MJ and Rosengren RJ: Role of epigallocatechin gallate (EGCG) in the treatment of breast and prostate cancer. Life Sci 79: 2329-2336, 2006.

5. Dona M, Dell'Aica I, Calabrese F, et al: Neutrophil restraint by green tea: inhibition of inflammation, associated angiogenesis, and pulmonary fibrosis. J Immunol 170: 4335-4341, 2003.

6. Cavet ME, Harrington KL, Vollmer TR, Ward KW and Zhang JZ: Anti-inflammatory and anti-oxidative effects of the green tea polyphenol epigallocatechin gallate in human corneal epithelial cells. Mol Vis 17: 533-542, 2011.

7. Katiyar SK, Afaq F,Perez A and Mukhtar H: Green tea polyphenol (-)-epigallocatechin-3-gallate treatment of human skin inhibits ultraviolet radiation-induced oxidative stress. Carcinogenesis 22: 287-294, 2001.

8. Meeran SM, Mantena SK, Elmets CA and Katiyar SK: (-)-Epigallocatechin-3-gallate prevents photocarcinogenesis in mice through interleukin-12-dependent DNA repair. Cancer Res 66: 5512-5520, 2006.

9. Kim SY, Kim DS, Kwon SB, et al: Protective effects of EGCG on UVB-induced damage in living skin equivalents. Arch Pharm Res 28: 784-790, 2005.

10. Chen W, Dong Z, Valcic S, Timmermann BN and Bowden GT: Inhibition of ultraviolet B-induced c-fos gene expression and p38 mitogen-activated protein kinase activation by (-)-epigallocatechin gallate in a human keratinocyte cell line. Mol Carcinog 24: 79-84, 1999.

11. Xia J, Song X, Bi Z, Chu W and Wan Y: UV-induced NF- $\kappa B$ activation and expression of IL-6 is attenuated by (-)-epigallocatechin-3-gallate in cultured human keratinocytes in vitro. Int J Mol Med 16: 943-950, 2005.

12. Bae JY, Choi JS, Choi YJ, et al: (-)Epigallocatechin gallate hampers collagen destruction and collagenase activation in ultraviolet-B-irradiated human dermal fibroblasts: involvement of mitogen-activated protein kinase. Food Chem Toxicol 46: 1298-1307, 2008

13. Ambros V: microRNAs: tiny regulators with great potential. Cell 107: 823-826, 2001.

14. Bartel DP: MicroRNAs: genomics, biogenesis, mechanism, and function. Cell 116: 281-297, 2004.

15. Yi R, Poy MN, Stoffel M and Fuchs E: A skin microRNA promotes differentiation by repressing 'stemness'. Nature 452: 225-229, 2008

16. Yi R, Pasolli HA, Landthaler M, et al: DGCR8-dependent microRNA biogenesis is essential for skin development. Proc Natl Acad Sci USA 106: 498-502, 2009.

17. Zhou BR, Xu Y, Permatasari F, et al: Characterization of the miRNA profile in UVB-irradiated normal human keratinocytes. Exp Dermatol 21: 317-319, 2012.

18. Nakagawa H, Hasumi K, Woo JT, Nagai K and Wachi M: Generation of hydrogen peroxide primarily contributes to the induction of $\mathrm{Fe}(\mathrm{II})$-dependent apoptosis in Jurkat cells by (-)-epigallocatechin gallate. Carcinogenesis 25: 1567-1574, 2004.

19. Muthusamy V and Piva TJ: The UV response of the skin: a review of the MAPK, NFkappaB and TNFalpha signal transduction pathways. Arch Dermatol Res 302: 5-17, 2010.

20. Yao K, Zhang L, Zhang Y, Ye P and Zhu N: The flavonoid, fisetin, inhibits UV radiation-induced oxidative stress and the activation of NF-kappaB and MAPK signaling in human lens epithelial cells. Mol Vis 14: 1865-1871, 2008.

21. Gu M, Dhanalakshmi S, Mohan S, Singh RP and Agarwal R: Silibinin inhibits ultraviolet $\mathrm{B}$ radiation-induced mitogenic and survival signaling, and associated biological responses in SKH-1 mouse skin. Carcinogenesis 26: 1404-1413, 2005.

22. Kim DS, Kim SY, Lee JE, et al: Sphingosine-1-phosphateinduced ERK activation protects human melanocytes from UVB-induced apoptosis. Arch Pharm Res 26: 739-746, 2003.

23. Sharma SD, Meeran SM and Katiyar SK: Dietary grape seed proanthocyanidins inhibit UVB-induced oxidative stress and activation of mitogen-activated protein kinases and nuclear factor-kappaB signaling in in vivo SKH-1 hairless mice. Mol Cancer Ther 6: 995-1005, 2007. 
24. Tsang WP and Kwok TT: Epigallocatechin gallate up-regulation of miR-16 and induction of apoptosis in human cancer cells. J Nutr Biochem 21: 140-146, 2010.

25. Wang H, Bian S and Yang CS: Green tea polyphenol EGCG suppresses lung cancer cell grow th through upregulating miR-210 expression caused by stabilizing HIF-1 $\alpha$. Carcinogenesis 32: 1881-1889, 2011.

26. Liu H and Kohane IS: Tissue and process specific microRNAmRNA co-expression in mammalian development and malignancy. PLoS One 4: e5436, 2009.

27. $\mathrm{Hu} \mathrm{HY}$, Guo S, Xi J, et al: MicroRNA expression and regulation in human, chimpanzee, and macaque brains. PLoS Genet 7: e1002327, 2011.
28. Uchida Y, Chiyomaru T, Enokida H, et al: MiR-133a induces apoptosis through direct regulation of GSTP1 in bladder cancer cell lines. Urol Oncol: Mar. 9, 2011 (Epub ahead of print).

29. Incoronato M, Garofalo M, Urso L, et al: miR-212 increases tumor necrosis factor-related apoptosis-inducing ligand sensitivity in non-small cell lung cancer by targeting the antiapoptotic protein PED. Cancer Res 70: 3638-3646, 2010.

30. Shin S, Moon KC, Park KU and Ha E: MicroRNA-513a-5p mediates TNF- $\alpha$ and LPS induced apoptosis via downregulation of X-linked inhibitor of apoptotic protein in endothelial cells. Biochimie 94: 1431-1436, 2012. 